\title{
PRODUKSI JAGUNG MANADO KUNING PADA JARAK TANAM DAN DOSIS PUPUK NITROGEN BERBEDA
}

\section{PRODUCTION OF MANADO KUNING CORN ON DIFFERENCES OF PLANTING DISTANCE AND NITROGEN FERTILIZER DOSES}

\author{
Rony H. Erungan1), D. S. Runtunuwu2), dan J. E. X. Rogi2) \\ 1)Dinas Pertanian dan Peternakan Provinsi Sulawesi Utara \\ 2)Fakultas Pertanian Unsrat Manado
}

\begin{abstract}
Purpose of this study was to determine the effect of different planting distance and different doses of nitrogen fertilizer on production of Manado Kuning corn. The research was conducted in the village of Subdistrict Regency Talikuran, Tompaso District Minahasa Regency from March to July 2012. The results was found that, the height of plant Manado Kuning corn ranged from $2.66 \mathrm{~m}$ to $2.81 \mathrm{~m}$. Height lies cob ranged from $1.64 \mathrm{~m}$ to $1.80 \mathrm{~m}$. Cob length ranged from $14.17 \mathrm{~cm}$ to $15,42 \mathrm{~cm}$. Similarly, different cob diameter of each type was different treatment. The average diameter of ranged from 4.09 $\mathrm{cm}$ to $4.34 \mathrm{~cm}$. Effect of plant spacing on cob diameter showed significant differences in spacing of $80 \mathrm{x}$ $20 \mathrm{~cm}$ produced diameter cobs, by $4.14 \mathrm{~cm}$; the spacing of $80 \times 30 \mathrm{~cm}$ resulted in the diameter of 4.28 $\mathrm{cm}$. As with the treatment history of planting, fertilizer treatments showed significant differences of cob diameter, with a fertilizer dose of $100 \mathrm{~kg} / \mathrm{ha}$ yield maize by $4.09 \mathrm{~cm}$ diameter, with a fertilizer dose of $150 \mathrm{~kg} / \mathrm{ha}$ yield a diameter of $4.20 \mathrm{~cm}$, and the treatment dose of fertilizer $200 \mathrm{~kg} / \mathrm{ha}$ yield $4.34 \mathrm{~cm}$ diameter. The number of lines is not affected by the above two kinds of treatment. Effect of plant spacing on seed weight per cob was, on spacing of $80 \times 20 \mathrm{~cm}$ produced seed weight of $97.27 \mathrm{~g}$, the spacing of $80 \times 30 \mathrm{~cm}$ produced seed weight of $109.16 \mathrm{~g}$. Effect of different doses of fertilizer are the dose of $100 \mathrm{~kg} / \mathrm{ha}$ yield seed weight of $94.18 \mathrm{~g}$, with a dose of $150 \mathrm{~kg} / \mathrm{ha}$ yield of $99.79 \mathrm{~g}$ seed weight, and with a dose of $200 \mathrm{~kg} / \mathrm{ha}$ yield seed weight of $115.68 \mathrm{~g}$.
\end{abstract}

Keywords: planting distance, doses of fertilizer

\begin{abstract}
ABSTRAK
Tujuan penelitian ini adalah untuk mengetahui pengaruh jarak tanam dan dosis pupuk nitrogen yang berbeda terhadap produksi jagung Manado Kuning. Penelitian dilaksanakan di Desa Talikuran Kecamatan Tompaso Kabupaten Minahasa pada bulan Maret sampai dengan bulan Juli 2012. Hasil penelitian ditemukan bahwa tinggi tanaman jagung Manado Kuning berkisar dari 2,66 m sampai dengan 2,81 $\mathrm{m}$. Tinggi letak tongkol berkisar antara 1,64 m sampai dengan 1,80 m. Panjang tongkol berkisar $14,17 \mathrm{~cm}$ sampai dengan 15,42 cm. Demikian dengan diameter tongkol berbeda tiap jenis perlakuan. Rata-rata diameter tongkol berkisar $4,09 \mathrm{~cm}$ sampai $4,34 \mathrm{~cm}$. Pengaruh jarak tanam terhadap diameter tongkol menunjukan perbedaan yang signifikan, pada jarak tanam $80 \times 20 \mathrm{~cm}$ menghasilkan diameter tongkol sebesar 4,14 cm, pada jarak tanam $80 \times 30 \mathrm{~cm}$ menghasilkan diameter sebesar 4,28 cm. Seperti halnya dengan perlakuan jarak tanam, perlakuan dosis pupuk menunjukan perbedaan yang signifikan terhadap diameter tongkol, dengan dosis pupuk $100 \mathrm{~kg} / \mathrm{ha}$ menghasilkan diameter jagung sebesar 4,09 cm, dengan dosis pupuk $150 \mathrm{~kg} / \mathrm{ha}$ menghasilkan diameter sebesar $4,20 \mathrm{~cm}$, dan dengan perlakuan dosis pupuk $200 \mathrm{~kg} / \mathrm{ha}$ menghasilkan diameter $4,34 \mathrm{~cm}$. Jumlah baris tidak dipengaruhi oleh kedua macam perlakuan di atas. Pengaruh jarak tanam terhadap berat biji per tongkol adalah, pada jarak tanam $80 \times 20 \mathrm{~cm}$ menghasilkan berat biji sebesar $97,27 \mathrm{~g}$, pada jarak tanam $80 \times 30 \mathrm{~cm}$ menghasilkan berat biji sebesar 109,16 g. Pengaruh perbedaan dosis pupuk adalah; pada dosis 100 $\mathrm{kg} / \mathrm{ha}$ menghasilkan berat biji $94,18 \mathrm{~g}$, dengan dosis $150 \mathrm{~kg} / \mathrm{ha}$ menghasilkan berat biji sebesar $\quad 99,79$ $\mathrm{g}$, dan dengan dosis $200 \mathrm{~kg} / \mathrm{ha}$ menghasilkan berat biji sebesar 115,68 g.
\end{abstract}

Kata kunci: jarak tanam, dosis pupuk

Eugenia Volume 18 No. 3 Desember 2012 


\section{PENDAHULUAN}

Jagung sampai saat ini masih merupakan komoditi strategis kedua setelah padi karena Jagung merupakan salah satu komoditas serealia yang mempunyai nilai ekonomis tinggi. Peranan jagung selain sebagai pangan (food) dan pakan (feed), sekarang banyak digunakan sebagai bahan baku energi (fuel) serta bahan baku industri lainnya yang kebutuhannya setiap tahun terus mengalami peningkatan.

Produksi jagung di Provinsi Sulawesi Utara masih berpotensi ditingkatkan melalui penggunaan benih unggul bermutu, penerapan teknologi budidaya yang benar, peningkatan luas tanam melalui pemanfaatan lahan tidur dan lahan marginal yang masih banyak ditemukan di daerah ini maupun memanfatkan lahan di antara pohon kelapa. Di Sulawesi Utara luas lahan luas lahan pengembangan pohon kelapa seluas $277.649 \mathrm{Ha}$ (Dinas Perkebunan Sulut, 2012).

Jagung Manado Kuning adalah jenis jagung bersari bebas. Dinamakan jagung bersari bebas (open pollinated crop) karena hampir $95 \%$ persarian jagung berasal dari serbuk sari tanaman lain, dan hanya $5 \%$ yang berasal dari serbuk sari sendiri. Tipe jagung Manado Kuning digolongkan pada tipe flint atau mutiara. Biji jagung tipe flint atau mutiara berbentuk bulat licin, mengkilap, dan keras. Bagian pati yang keras terdapat di bagian atas biji, pada saat masak bagian atas biji mengkerut bersama-sama sehingga permukaan biji bagian atas licin dan bulat. Varietas lokal jagung di Indonesia umumnya tergolong ke dalam tipe biji mutiara, tipe ini disukai petani karena tahan hama gudang (Subekiti dkk., 2006)

Berdasarkan observasi di lapangan masih banyak petani yang mengembangkan jagung komposit baik varietas yang sudah dilepas maupun varietas lokal lainnya. Alasan petani lebih senang menanam jagung komposit karena jagung komposit mudah dan sederhana dikembangkan, benih dapat secara lebih cepat diperbanyak, benih dapat digunakan beberapa generasi, dapat diperbanyak oleh petani sendiri sehingga mengurangi ketergantungan petani kepada pihak lain, daya adaptasi lebih luas, dapat dikembangkan pada lahan margi- nal maupun lahan subur, dan biaya produksi lebih rendah (Pangaribuan, 2010)

Jagung Manado Kuning, walaupun potensi produktivitas relatif lebih rendah jika dibandingkan dengan jenis hibrida maupun jagung komposit yang dilepas oleh Kementerian Pertanian, akan tetapi sampai sekarang masih banyak ditanam oleh petani di daerah ini. Ada beberapa hal yang menjadi alasan sehingga jagung ini tetap dibudidayakan, sebagaimana ciri-ciri varietas lokal umumnya, jagung Manado Kuning lebih toleran terhadap naungan, lebih tahan hama sitopilus, mampu memberikan hasil memuaskan pada pemupukan yang tidak optimal, bahkan masih mampu memberikan hasil pada lahan marginal sekalipun, dan yang paling utama adalah tanaman jagung Manado Kuning menjadi pakan yang disukai ternak sapi.

Setelah sekian lama dikembangkan di daerah ini sebagai jagung bersari bebas, maka dapat dipastikan telah terjadi perubahan karakter akibat terjadinya persilangan dengan varietas lainnya, bahkan penampilan agronomik jagung ini di tiap sentra pengembangan sudah berbeda. Oleh karena itu, sehubungan dengan keunggulan komparatif seperti tersebut di atas, maka perlu ada upaya untuk mempertahankan eksistensi jagung ini dalam rangka pengembangan untuk peningkatan produksi maupun dalam rangka pelestarian plasma nutfah sebagai bahan dasar perakitan jenis jagung baru.

Penelitian bertujuan untuk mengevaluasi penampilan agronomis jagung Manado Kuning pada populasi dan pupuk nitrogen yang berbeda. Manfaat penelitian ini adalah dengan tersedianya data penampilan karakter agronomis jagung Manado Kuning, pengembangan jagung ini ke depan dapat dilakukan sesuai dengan kebutuhan petani di daerah ini.

\section{METODE PENELITIAN}

Penelitian ini dilakukan di Desa Talikuran Kecamatan Tompaso, dengan lama penelitian 5 bulan, yaitu mulai Maret 2012 sampai dengan Juli 2012.

Benih Jagung Manado Kuning ditanam menggunakan dua jarak tanam, yaitu: $80 \mathrm{~cm} \times 20$ 
cm (JT1) dan $80 \mathrm{~cm} \times 30 \mathrm{~cm}$ (JT2), dengan pemupukan susulan dosis yang berbeda, yaitu 100 $\mathrm{kg}$ urea/ha (P1), $150 \mathrm{~kg}$ urea/ha (P2), dan $200 \mathrm{~kg}$ urea/ha (P3), dan untuk mencukupi kebutuhan tanaman akan unsur $\mathrm{P}$ dan $\mathrm{K}$, tanaman akan diberi pupuk majemuk NPK, yaitu Phonska dengan dosis $150 \mathrm{~kg} / \mathrm{ha}$. Dengan demikian perlakuan yang akan diteliti ada sebanyak 6 perlakuan, sebagai berikut: JT1P1, yaitu jarak tanam $80 \mathrm{~cm} \times 20 \mathrm{~cm}+$ pupuk $100 \mathrm{~kg}$ urea/ha; JT1P2, yaitu jarak tanam $80 \mathrm{~cm} \mathrm{x}$ $20 \mathrm{~cm}+$ pupuk $150 \mathrm{~kg}$ urea/ha; JT1P3, yaitu jarak tanam $80 \mathrm{~cm} \times 20 \mathrm{~cm}+$ pupuk $200 \mathrm{~kg}$ urea/ha; JT2P1, yaitu jarak tanam $80 \mathrm{~cm} \times 30 \mathrm{~cm}+$ pupuk $100 \mathrm{~kg}$ urea/ha; JT2P2, yaitu jarak tanam $80 \mathrm{~cm} x$ $30 \mathrm{~cm}+$ pupuk $150 \mathrm{~kg}$ urea/ha; JT2P3, yaitu jarak tanam $80 \mathrm{~cm} \times 30 \mathrm{~cm}+$ pupuk $200 \mathrm{~kg}$ urea/ha.

Karakter agronomis yang akan diamati adalah sebagai berikut: tinggi tanaman, tinggi letak tongkol, panjang tongkol, diameter tongkol, jumlah baris dalam tongkol, berat biji jagung.

Data dianalisis dengan analisis ragam dan dilanjutkan dengan uji BNT $5 \%$.

Alat yang akan digunakan dalam penelitian ini yaitu: bajak, kamera, timbangan analitik, pisau, alat tulis menulis, tugal, dan hand sprayer.

Bahan yang digunakan adalah benih Jagung Manado yang akan diambil dari hasil panen petani di Desa Wineru, Pupuk Phonska dan Urea, pestisida, dan lain-lain.

\section{HASIL DAN PEMBAHASAN}

\section{Tinggi Tanaman Jagung}

Rata-rata tinggi tanaman jagung Manado Kuning berkisar dari 2,66 m sampai dengan 2,81 m, tetapi berdasarkan analisa sidik ragam ternyata tidak ada perbedaan yang nyata. Rata-rata tinggi tanaman jagung yang ditanam dengan jarak dan dosis pupuk nitrogen yang berbeda disajikan pada Tabel 1.

Berdasar Tabel 1 ternyata tinggi tanaman terendah $(2,66 \mathrm{~m})$ dijumpai pada perlakuan JT1P3 dan rata-rata paling tinggi $(2,81 \mathrm{~m})$ dijumpai pada perlakuan JT2P2.
Tabel 1. Rata-rata Tinggi Tanaman Jagung

(Table 1. AverageHeightof Corn)

\begin{tabular}{cc}
\hline Perlakuan & Rata-rata $(\mathrm{m})$ \\
\hline JT1P1 & 2,77 \\
JT1P2 & 2,79 \\
JT1P3 & 2,66 \\
JT2P1 & 2,68 \\
JT2P2 & 2,81 \\
JT2P3 & 2,77 \\
\hline
\end{tabular}

Ket. $\mathrm{JT}=$ jarak tanam, $\quad \mathrm{P}=$ Pupuk

\section{Tinggi Tongkol}

Rata-rata tinggi tongkol jagung Manado Kuning berkisar dari 1,64 m sampai dengan 1,80 m. Berdasarkan hasil analisa sidik ragam ternyata tidak terdapat perbedaan yang nyata. Rata-rata tinggi tongkol tanaman jagung Manado Kuning yang ditanam dengan jarak tanam dan dosis pupuk nitrogen yang berbeda disajikan pada Tabel 2 .

Tabel 2. Rata-rata Tinggi Tongkol Jagung

(Table 2. Average Height of Cob on Plants)

\begin{tabular}{cc}
\hline Perlakuan & Rata-rata $(\mathrm{m})$ \\
\hline JT1P1 & 1,73 \\
JT1P2 & 1,80 \\
JT1P3 & 1,64 \\
JT2P1 & 1,64 \\
JT2P2 & 1,73 \\
JT2P3 & 1,72 \\
\hline
\end{tabular}

Berdasarkan data pada Tabel 2 ternyata tinggi tongkol terendah $(1,64 \mathrm{~m})$ dijumpai pada perlakuan JT1P3 dan JT2p1 sedangkan tertinggi (1,80 m) dijumpai pada perlakuan JT1P2.

\section{Panjang Tongkol}

Rata-rata panjang tongkol jagung Manado Kuning dipengaruhi secara nyata oleh pemupukan nitrogen. Panjang tongkol berkisar $14,17 \mathrm{~cm}$ sampai $15,42 \mathrm{~cm}$ seperti pada Tabel 3.

Berdasarkan data pada Tabel 3 ternyata dengan pemupukan nitrogen $100 \mathrm{~kg} / \mathrm{ha}$, rata-rata panjang tongkol sebesar $14,17 \mathrm{~cm}$, pemupukan nitrogen $150 \mathrm{~kg} / \mathrm{ha}$, rata-rata panjang tongkol 14,79 $\mathrm{cm}$ dan pemupukan nitrogen $200 \mathrm{~kg} / \mathrm{ha}$, rata-rata panjang tongkol sebesar $15,42 \mathrm{~cm}$. 
Tabel 3. Pengaruh Pupuk Terhadap Panjang Tongkol Jagung

(Table 3. Effect of Different Doses of Fertilizer on Long of Cob)

\begin{tabular}{cc}
\hline Perlakuan & Rata-rata $(\mathrm{cm})$ \\
\hline P1 & $14,17 \mathrm{a}$ \\
P2 & $14,79 \mathrm{~b}$ \\
P3 & $15,42 \mathrm{C}$ \\
BNT 5\% & 0,53 \\
\hline Keterangan: & Angka yang dikuti dengan huruf
\end{tabular}
yang sama tidak berbeda nyata berdasarkan uji BNT 5\%.

\section{Diameter Tongkol}

Rata-rata diameter tongkol jagung Manado Kuning dipengaruhi oleh jarak tanam dan pemupukan nitrogen. Rata-rata diameter tongkol berkisar 4,09 cm sampai 4,34 cm seperti pada Tabel 4 dan Tabel 5.

Tabel 4. Pengaruh Jarak Tanam Terhadap Diameter Tongkol Jagung

(Table 4. Effect of Different Planting Distance on Diameter of $\mathrm{Cob}$ )

\begin{tabular}{cc}
\hline Perlakuan & Rata-rata $(\mathrm{cm})$ \\
\hline JT1 & $4,14 \mathrm{a}$ \\
JT2 & $4,28 \mathrm{~b}$ \\
BNT 5\% & 0,12 \\
\hline Keterangan: & Angka yang diikuti dengan huruf
\end{tabular}
yang sama tidak berbeda nyata berdasarkan uji BNT 5\%.

Tabel 5. Pengaruh Pupuk Terhadap Diameter Tongkol Jagung

(Table 5. Effect of Different Doses of Fertilizeron Diameter of Cob)

\begin{tabular}{cc}
\hline \multicolumn{1}{c}{ Perlakuan } & Rata-rata $(\mathrm{cm})$ \\
\hline P1 & $4,09 \mathrm{a}$ \\
P2 & $4,20 \mathrm{ab}$ \\
P3 & $4,34 \mathrm{~b}$ \\
BNT 5\% & 0,15 \\
\hline Keterangan : & Angka yang diikuti dengan huruf
\end{tabular}
yang sama tidak berbeda nyata berdasarkan uji BNT 5\%.

Berdasarkan data pada Tabel 4 ternyata pada jarak tanam $80 \times 20 \mathrm{~cm}$, diameter tongkol sebesar $4,14 \mathrm{~cm}$ dan pada jarak tanam $80 \times 30 \mathrm{~cm}$, diameter tongkol sebesar 4,28 cm.

Berdasarkan data pada Tabel 5, ternyata pada pemupukan nitrogen $100 \mathrm{~kg} / \mathrm{Ha}$, diameter tongkol sebesar $4,09 \mathrm{~cm}$, pada pemupukan nitrogen $150 \mathrm{~kg} / \mathrm{Ha}$, diameter tongkol sebesar $4,20 \mathrm{~cm}$, dan pada pemupukan nitrogen $200 \mathrm{~kg} / \mathrm{Ha}$, diameter tongkol sebesar $4,34 \mathrm{~cm}$.

\section{Jumlah Baris}

Rata-rata jumlah baris jagung Manado Kuning tidak dipengaruhi oleh jarak tanaman (populasi) dan pemupukan nitrogen. Rata-rata jumlah baris berkisar 11,33 sampai 12,60 baris.

Tabel 6. Rata-rata Jumlah Baris

(Table 6. Avarage Number of Rows in the Cob)

\begin{tabular}{cc}
\hline Perlakuan & Rata-rata \\
\hline JT1P1 & 11,33 \\
JT1P2 & 12,27 \\
JT1P3 & 12,53 \\
JT2P1 & 12,47 \\
JT2P2 & 12,53 \\
JT2P3 & 12,60 \\
\hline
\end{tabular}

Berdasarkan data pada Tabel 6, ternyata jumlah baris terendah $(11,33)$ dijumpai pada perlakuan JT1P1 sedangkan jumlah baris tertinggi $(12,60)$ dijumpai pada perlakuan JT2P3.

\section{Berat Biji Per Tongkol}

Rata-rata berat biji jagung Manado Kuning dipengaruhi oleh jarak tanam dan pemupukan nitrogen. Rata-rata berat biji per tongkol berkisar 94,18 g sampai dengan 115,68 g (Tabel 7 dan Tabel 8)

Tabel 7. Pengaruh Jarak Tanam Terhadap Berat Biji PerTongkol Jagung

(Table 7. Effect of Different Planting Distance on Seed Weight)

\begin{tabular}{cc}
\hline Perlakuan & Rata-rata $(\mathrm{g})$ \\
\hline JT1 & $97,27 \mathrm{a}$ \\
JT2 & $109,16 \mathrm{~b}$
\end{tabular}

\begin{tabular}{rl} 
BNT $5 \%$ & 8,02 \\
\hline Keterangan: & Angka yang diikuti dengan huruf \\
yang sama tidak berbeda nyata \\
berdasarkan uji BNT $5 \%$.
\end{tabular}


Berdasarkan data pada Tabel 7, ternyata perlakuan jarak tanam JT1 berat biji per tongkol sebesar 97,27 g, dan jarak tanam JT2 berat biji per tongkol sebesar 109,16 g.

Tabel 8. Pengaruh pupuk Terhadap Berat Biji Per Tongkol Jagung

(Table 8. Effect Different Doses of Fertilizer on Seed Weight)

\begin{tabular}{lc}
\hline Perlakuan & Rata-rata(g) \\
\hline P1 & $94,18 \mathrm{a}$ \\
P2 & $99,79 \mathrm{a}$ \\
P3 & $115,68 \mathrm{~b}$ \\
BNT 5\% & 9,82 \\
\hline Keterangan : & Angka yang diikuti dengan huruf \\
& yang sama tidak berbeda nyata \\
& berdasarkan uji BNT 5\%.
\end{tabular}

Berdasarkan data pada Tabel 8, ternyata perlakuan pemupukan nitrogen $100 \mathrm{~kg} / \mathrm{ha}(\mathrm{P} 1)$ berat biji per tongkol sebesar $94,18 \mathrm{~g}$, pemupukan nitrogen sebesar $150 \mathrm{~kg} / \mathrm{ha}$, berat biji per tongkol 99,79 g dan pemupukan nitrogen $200 \mathrm{~kg} / \mathrm{ha}$ menghasilkan berat biji per tongkol sebesar 115,68 g.

Ada penambahan ukuran panjang ratarata tongkol jagung oleh adanya penambahan dosis pupuk urea, dengan penambahan pupuk urea dari $100 \mathrm{~kg} / \mathrm{ha}$ menjadi $150 \mathrm{~kg} / \mathrm{ha}$, terjadi penambahan $0,62 \mathrm{~cm}$, penambahan dosis dari $150-200 \mathrm{~kg} / \mathrm{ha}$ bertambah $0,63 \mathrm{~cm}$, atau bertambah $1,25 \mathrm{~cm}$ jika dibandingkan pada dosis $100 \mathrm{~kg} / \mathrm{ha}$. Demikian halnya dengan ukuran diameter tongkol, dengan penambahan dosis pupuk dari $100 \mathrm{~kg} / \mathrm{ha}$ menjadi 150 $\mathrm{kg} / \mathrm{ha}$, terjadi penambahan diameter tongkol sebesar $0,11 \mathrm{~cm}$, pada penambahan dosis dari 150 $200 \mathrm{~kg} / \mathrm{ha}$ bertambah $0,14 \mathrm{~cm}$ atau bertambah 0,25 $\mathrm{cm}$ jika dibandingkan pada dosis $100 \mathrm{~kg} / \mathrm{ha}$. Untuk ukuran berat bijipun menunjukan penambahan yakni, pada penambahan dosis pupuk dari 100 $\mathrm{kg} / \mathrm{ha}$ menjadi $150 \mathrm{~kg} / \mathrm{ha}$, ukuran berat biji bertambah sebesar $5,61 \mathrm{~g}$, pada penambahan dosis dari 150- $200 \mathrm{~kg} / \mathrm{ha}$, bertambah $15,89 \mathrm{~g}$ atau bertambah $21,50 \mathrm{~g}$ jika dibandingkan pada dosis $100 \mathrm{~kg} / \mathrm{ha}$. Penambahan panjang tongkol, diameter tongkol serta berat biji pertongkol ini dipengaruh langsung oleh ketersedianan hara Nitrogen dalam tanah. Sebagian besar unsur Nitrogen di bawah ke titik tumbuh, batang, daun, bunga jantan lalu dialihkan ke biji.Unsur Nitrogen terus menerus diserap tanaman sampai tanaman mencapai matang (Syafruddin et. al., 2006). Pada saat pembungaan (bunga jantan) tanaman jagung telah mengabsorbsi sebanyak $50 \%$ Nitrogen dari seluruh kebutuhannya (Sutoro et. al., 1982). Dengan demikian karena ada ketersediaan unsur hara Nitrogen, maka penambahan panjang, diameter dan berat biji dapat berlangsung lebih banyak.

Jumlah total tambahan hara Nitrogen yang diberikan dalam penelitian ini yakni pada pemupukan dasar dengan dosis $150 \mathrm{~kg} / \mathrm{ha}$ berarti mengandung unsur nitrogen sebesar $30 \mathrm{~kg}$ (konsentrasi $\mathrm{N}$ dalam pupuk phonska sebesar $20 \%$ ), ditambah dengan pemupukan susulan 1). $100 \mathrm{~kg} \mathrm{~N} / \mathrm{ha}$ atau $46 \mathrm{~kg}$ nitrogen (konsentrasi $\mathrm{N}$ dalam urea sebesar $46 \%$ ), maka total nitrogen dosis I sebesar $76 \mathrm{~kg}, 2$ ) pupuk susulan $150 \mathrm{~kg} \mathrm{~N} / \mathrm{ha}$ atau $69 \mathrm{~kg}$ nitrogen, maka total nitrogen dosis II sebesar $99 \mathrm{~kg}$, dan 3). Pupuk susulan $200 \mathrm{~kg} / \mathrm{Ha}$ atau $96 \mathrm{~kg}$ nitrogen, maka total nitrogen dosis III sebesar $126 \mathrm{~kg}$. Ditambah dengan ketersediaan nitrogen yang sudah ada dalam tanah, maka total ketersediaan nitrogen dalam tanah melebihi perhitungan di atas. Kebutuhan nitrogen sejak fase awal sampai masak fisiologis, tanaman jagung memerlukan sekitar 120$180 \mathrm{~kg} \mathrm{~N} / \mathrm{ha}$ (Halliday and Trenkel, 1992).

Tidak ada interaksi antara perlakuan jarak tanam dan dosis pupuk dalam penelitian ini, namun bilamana dihitung total produksi jagung berdasarkan dosis pupuk yang diberikan, maka dengan asumsi populasi per hektar sebanyak 41.667 pohon (jarak tanam $80 \times 30 \mathrm{~cm}$ ), maka produksi jagung pipilan kering adalah: Dosis pupuk susulan 100 $\mathrm{kg} / \mathrm{ha}, 41.667$ pohon $\times 94,18 \mathrm{~g}$ (rata-rata per tongkol) menghasilkan produksi 3,92 ton/ha, dengan pupuk susulan $150 \mathrm{~kg} / \mathrm{ha}, 41.667$ pohon $\mathrm{x}$ 99,79 g menghasilkan produksi 4,16 ton/ha, dan dengan pupuk susulan $200 \mathrm{~kg} / \mathrm{ha}, 41.667$ pohon $\mathrm{x}$ 115,68 g menghasilkan produksi 4,82 ton/ha. Bilamana produksi dihitung pada jumlah populasi 62.500 pohon (jarak tanam $80 \times 20 \mathrm{~cm}$ ), maka sama dengan perhitungan di atas, dengan pupuk susulan dosis $100 \mathrm{~kg} / \mathrm{ha}$ meng-hasilkan 5,89 ton/ha, dengan pupuk susulan dosis $150 \mathrm{~kg} / \mathrm{ha}$ 
menghasilkan 6,24 ton/ha, dan dengan pupuk susulan dosis $200 \mathrm{~kg} / \mathrm{ha}$ menghasilkan 7,23 ton/ha.

Hasil penelitian ini menunjukan adanya kenaikan linier berbading lurus penambahan pupuk dari $100 \mathrm{~kg} / \mathrm{ha}, 150 \mathrm{~kg} / \mathrm{ha}$, sampai $200 \mathrm{~kg} / \mathrm{ha}$ dengan penambahan panjang tongkol, serta penambahan diameter tongkol, dan berat biji pertongkol. Beberapa hasil penelitian respon tanaman jagung terhadap perlakuan pupuk urea yang berbeda dosis, penelitian-penelitian ini menunjukan kesamaan hasil antara lain ; 1) Penelitian yang dilaksanakan di Daerah Goa Sulawesi Selatan pada jagung varietas Lamuru dengan perlakuan 4 dosis pupuk berbeda yaitu; 200 $\mathrm{kg} / \mathrm{ha}, 300 \mathrm{~kg} / \mathrm{ha}, 400 \mathrm{~kg} / \mathrm{ha}$ dan $500 \mathrm{~kg} / \mathrm{ha}$. Hasil penelitian menunjukan hasil biji tertinggi sebesar 7,5 ton diperoleh pada perlakuan pupuk urea 300 $\mathrm{kg} / \mathrm{Ha}$ (Akil, M., 2009). 2) Ada juga penelitian yang dilaksanakan di rumah kaca Balai Penelitian Tanaman Serealia Maros Sulawesi Selatan, hasilnya menunjukan bahwa biji yang sesuai dengan standar benih bermutu untuk varietas Lamuru, Sukmaraga, Bisi 2 dan Pionir berasal dari tanaman yang dipupuk dengan dosis antara $200-300 \mathrm{~kg} / \mathrm{ha}$ (Oom Komalasari dan Fauziah Koes, 2009). Penelitian berikutnya adalah 3).Penelitian efisiensi pemupukan jagung pada lahan kering beriklim kering, dilaksanakan di Desa Sambelia, Kecamatan Sambelia, Kabupaten Lombok Timur. NTB. Pemupukan dengan cara petani yakni $300 \mathrm{~kg} / \mathrm{ha}$ urea yang diberikan 2 kali secara tugal, lebih layak dipertahankan (Margaretha SL, 2009).

Jarak tanam juga mempengaruhi penambahan diameter dan berat biji tongkol, jarak tanam $80 \times 20 \mathrm{~cm}$ dibandingkan dengan jarak tanam $80 \times 30 \mathrm{~cm}$, rata-rata diameter bertambah $0,14 \mathrm{~cm}$ dan rata-rata berat biji bertambah $1,89 \mathrm{~g}$. Perbedaan ukuran diameter dan berat biji per tongkol dari kedua ukuran jarah tanam ini berhubungan dengan kompetisi tanaman dalam penggunaan cahaya, air, unsur hara dan ruang tumbuh (Irfan M., 1999). Denganh demikian pada populasi yang lebih renggang, tanaman memiliki kesempatan untuk memperoleh cahaya, unsur hara, air dan ruang tumbuh yang lebih banyak.

\section{KESIMPULAN DAN SARAN}

\section{Kesimpulan}

Dengan demikian dapat disimpulkan bahwa penampilan agronomis jagung Manado Kuning pada populasi dan pupuk nitrogen yang berbeda adalah: 1) Jagung Manado Kuning bersifat responsif terhadap pemberian pupuk nitrogen; 2) Penambahan pupuk nitrogen mampu meningkatkan panjang tongkol, diameter tongkol dan berat biji pertanaman; 3) Peningkatan dosis pupuk urea berbanding lurus dengan peningkatan produksi pipilan kering jagung Manado Kuning. Produksi terbesar diperoleh pada perlakuan pupuk susulan dengan dosis $200 \mathrm{~kg} / \mathrm{ha}$; 4) Penjarangan populasi atau penambahan jarak tanam mampu meningkatkan berat biji pertanaman serta ukuran diameter tongkol. Penambahan jarak tanam dari $80 \times 20 \mathrm{~cm}$ menjadi $80 \times 30 \mathrm{~cm}$ meningkatkan produksi pipilan kering jagung Manado Kuning; 5) Pengurangan populasi dan peningkatan pupuk susulan nitrogen tidak mempengaruhi secara nyata terhadap jumlah baris, tinggi tanaman, dan tinggi tongkol jagung Manado Kuning; 6) Jumlah baris tongkol jagung Manado Kuning sebanyak 10 - 16 baris.

\section{Saran}

Perlu dilakukan penelitian lanjutan untuk mengetahui jarak tanam ideal jagung Manado Kuning yang mampu menghasilkan produksi pipilan kering maksimal.

Jagung Manado Kuning adalah jenis tanaman bersari bebas, mengingat penyebaran jagung Manado Kuning tersebar luas di daerah ini, maka tiap individu/kelompok tanaman jagung ini, telah mengalami perubahan yang berbeda-beda. Karena itu perlu dilakukan penelitian dengan mengambil sampel benih dari tiap-tiap sentra pengembangan, untuk mengetahui penciri jagung Manado Kuning yang akurat.

\section{DAFTAR PUSTAKA}

Anonim. 1998. Regional News Biological Nitrogen. Fixation for South and Southeast Asia. Vol 1. 
Badan Pusat Statistik Provinsi Sulawesi Utara. 2011. Espose Angka Sementara Tahun 2011 dan Angka Prediksi Tahun 2012 Produksi Tanaman Pangan Provinsi Sulawesi Utara.

Dinas Pertanian dan Peternakan Provinsi Sulawesi Utara. 2012. Laporan Tahunan.

FFTC (Food and Feertilizier Technology Center). 1994. Fertlizier Use and Sustainable Food Production. Food and Fertilizier Technology Center for The Asian and Pasific Center Region. Taipe. Taiwan. FFTC. Newsletter 104 (june 1994).

Kementerian Pertanian. 2012. Data Produksi dan Produktivitas Tanaman Pangan. www.Deptan.go.id.

Kementerian Pertanian. 2010. Rencana Strategis Kementerian Pertanian Tahun 2010-2014.
Margaretha SI., W. Ningsih, Subandi dan Zubachtioddin. 2006. Budidaya Tanaman Jagung dalam Jagung. Badan Litbang Pertanian Bogor.

Oom Komalasari dan Fauziah Koes. 2009. Pengaruh Kualitas Biji pada Berbagai Taraf Pemupukan Nitrogen Terhadap Vigor Benih Jagung. Prosiding Seminar Nasional. Balai Penelitian Tanaman Sereal Maros.

Syafrudin, Faesal, dan M. Akil. 2006. Pengelolaan Hara Pada Tanaman Jagung. Balai Penelitian Tanaman Sereal Maros.

Syamsul Bakhri. 2008. Budidaya Jagung dan Konsep Pengelolaan Tanaman Terpadu. Balai Pengkajian dan Pengembangan Teknologi Pertanian Sulawesi Tengah. 
